\title{
EDUCAÇÃO FÍSICA, GÊNERO E CINEMA: CONTRIBUIÇÕES PARA A FORMAÇÃO DOCENTE ${ }^{1}$
}

\author{
Ludmila Mourão \\ Universidade Federal de Juiz de Fora, Governador Valadares, Minas Gerais, Brasil. \\ João Paulo Fernandes Soares \\ Universidade Federal de Juiz de Fora, Governador Valadares, Minas Gerais, Brasil. \\ Ayra Lovisi \\ Universidade Federal de Juiz de Fora, Governador Valadares, Minas Gerais, Brasil. \\ Mariana Cristina Borges Novais \\ Universidade Federal de Juiz de Fora, Governador Valadares, Minas Gerais, Brasil.
}

\begin{abstract}
Resumo: O cinema pode ser considerado um veículo audiovisual dotado de complexa linguagem e eminente potencial educacional. Nesse sentido, o presente ensaio apresenta reflexões que partem de um aporte teórico em diálogo com experiências pedagógicas no campo da formação docente em Educação Física e cinema. Tal processo teve como objetivo articular o recurso imagético aos saberes e práticas docentes, ampliando as discussões sobre gênero nas práticas corporais e esportivas. Além dos debates, as experiências pedagógicas geraram diferentes produções acadêmicas que permitiram aos futuros docentes vivenciarem as contribuições do cinema como recurso capaz de estabelecer inter-relação entre a formação acadêmica e a sociedade a partir de reflexões e debates.
\end{abstract}

Palavras-Chave: Educação Física. Educação Superior. Cinema. Gênero.

\section{PHYSICAL EDUCATION, GENDER AND CINEMA: CONTRIBUTIONS TO TEACHER TRAINING}

\begin{abstract}
Cinema can be considered an audiovisual vehicle endowed with complex language and important educational potential. In that sense, this essay presents reflections that start from a theoretical contribution in dialogue with pedagogical experiences in the field of educational formation in Physical Education and cinema. Such a process aimed at articulating the image feature with the knowledge and teaching practices, expanding the discussions on gender in corporal and sports practices. In addition to the debates, the pedagogical experiences generated different academic productions that allowed future teachers to experience the contributions of cinema as a resource capable of establishing an interrelation between academic formation and society based on reflections and debates.

Keywords: Physical Education. College education. Cinema. Gender.
\end{abstract} 1 Este trabalho contou com o apoio da Coordenação de Aperfeiçoamento de Pessoal de Nível Superior (CAPES)
e da Fundação de Amparo à Pesquisa do Estado de Minas Gerais (FAPEMIG). 


\section{EDUCACIÓN FÍSICA, GÉNERO Y CINE: CONTRIBUCIONES PARA LA FORMA- CIÓN DOCENTE}

Resumen: El cine puede ser considerado un vehículo audiovisual dotado de complejo lenguaje y eminente potencial educativo. En este sentido, el presente ensayo presenta reflexiones que parten de un aporte teórico en diálogo con experiencias pedagógicas en el campo de la formación docente en Educación Física y cine. Tal proceso tuvo como objetivo articular el recurso de imagen a los saberes y prácticas docentes, ampliando las discusiones sobre género en las prácticas corporales y deportivas. Además de los debates, las experiencias pedagógicas generaron diferentes producciones académicas que permitieron a los futuros docentes vivir las contribuciones del cine como recurso capaz de establecer interrelación entre la formación académica y la sociedad a partir de reflexiones y debates. Palabras Clave: Educación Física. Educación universitaria. Cine. Género.

\section{Introdução}

As sociedades contemporâneas têm nas imagens um dos principais veículos de difusão de seus significados culturais, normas e valores. As imagens apresentam-se como potentes dispositivos $^{2}$ de subjetivação ${ }^{3}$, sendo, portanto, um meio pelo qual são instaurados processos em que os sujeitos se constituem e constituem formas de pensar, agir e sentir.

Dentre os artefatos imagéticos dessas sociedades, este ensaio se propôs a refletir sobre o cinema como um veículo audiovisual dotado de complexa linguagem para formar e educar. Para esse fim, contar histórias apresenta-se como uma forma de transmitir conhecimentos. $\mathrm{O}$ cinema não ficou imune a esse processo. Parte da percepção que temos da história da humanidade talvez esteja marcada pelo contato que temos/tivemos com as imagens cinematográficas (DUARTE, 2009), e parece ser por meio dessas imagens que determinadas experiências culturais, associadas a certas maneiras de assistir a filmes, acabam interagindo na produção de saberes, identidades, crenças e visões de mundo. Assim, podemos inferir que o cinema se apresenta como processo eminentemente educacional e pedagógico ${ }^{4}$.

Nessa perspectiva, os discursos ${ }^{5}$ e relações sociais estão presentes nas narrativas fílmicas de forma mimética, as quais estão carregadas de identidades formuladas por modos de ser, agir e pensar as diferenças sociais (OLIVEIRA-SILVA, 2013). Assim, a narrativa é um processo de escolha, de inclusão e exclusão de fatos e fatores, na busca de ampliar as atratividades das produções ao público ao qual é endereçado. Essas questões nos fazem refletir acerca das possibilidades pedagógicas do discurso cinematográfico, remetendo-nos a Fabris (2005, p. 21) que afirma que as narrativas fílmicas "nos interpelam de um modo avassalador, porque

\footnotetext{
2 Foucault define "dispositivo" como "um conjunto decididamente heterogêneo que engloba discursos, instituições, organizações arquitetônicas, decisões regulamentares, leis, medidas administrativas, enunciados científicos, proposições filosóficas, morais, filantrópicas. Em suma, o dito e o não dito são os elementos do dispositivo. $\mathrm{O}$ dispositivo é a rede que se pode tecer entre estes elementos" (FOUCAULT, 2012, p. 244).

3 Mais sobre os processos de subjetivação em interface com os processos educacionais ver Ferrari (2012).

4 No começo do século XX, já se utilizava o cinema como ferramenta para o desenvolvimento do conhecimento e aprendizagem na sala de aula. De acordo Bittencourt (2004, p. 371), um dos marcos desse processo foi "Jonathas Serrano, professor do Colégio Pedro II e conhecido autor de livros didáticos, que procurava desde 1912, incentivar seus colegas a recorrer de filmes de ficção ou documentários para facilitar o aprendizado da disciplina". Logo, seu uso como recurso didático não é uma novidade.

5 Os discursos podem ser entendidos como sistemas e códigos de significação que constituem o conjunto de enunciados de um determinado campo de saber, construídos historicamente dentro das relações de poder (FOUCAULT, 2011).
} 
não dispensam o prazer, o sonho e a imaginação". Suas histórias "mexem com nosso inconsciente" e "embaralham as fronteiras do que entendemos por realidade e ficção".

Segundo Martin (2009), a imagem traz a reprodução do real para, na sequência e em segundo plano, afetar nossos sentimentos e, por fim, em terceiro plano e sempre facultativamente, adquirir uma significação ideológica e moral. Consequentemente, as narrativas fílmicas tornam-se um dispositivo que expressa uma multiplicidade de sentidos da realidade, subjetivados por cada espectador com base em seus sentidos e na leitura que realizam das proposições gestadas pelas imagens. Isso ocorre, pois, por trás de cada receptor:

[...] existe um sujeito social dotado de valores, crenças, saberes e informações próprios de sua(s) cultura(s), que interage, de forma ativa, na produção do significado das mensagens [...] o espectador não é vazio nem, muito menos, tolo; suas experiências, sua visão de mundo e suas referências culturais interferem no modo como ele vê e interpreta os conteúdos da mídia. (DUARTE, 2009, p. 54).

Notadamente, as práticas pedagógicas exigem diferentes saberes; assim, as temáticas sobre os saberes dos professores vêm sendo abordadas sob diferentes perspectivas. Dentre elas, a proposta por Tardif $(2002$, p. 11) " [...] se assenta na ideia de que esse saber é social, embora sua existência dependa dos(as) docentes (mas não somente deles(as)) enquanto sujeitos empenhados numa prática". O autor defende que "[...] o saber dos professores é o saber deles e está relacionado com a pessoa e suas identidades, com sua experiência de vida e com sua história profissional, com as suas relações com os alunos em sala de aula e com os outros atores na instituição".

Grigolli (2003), em diálogo com Tardif (2002), sistematiza os saberes da formação profissional e assim os discrimina:

\begin{abstract}
Os saberes das disciplinas que correspondem às diversas áreas do conhecimento e integram a formação inicial e a formação contínua dos professores mediante as diversas disciplinas específicas que compõem os currículos dos cursos universitários. Os saberes curriculares que se referem aos conteúdos programáticos são recortes das diferentes áreas do conhecimento que constituem a cultura erudita e são selecionados e definidos pelos sistemas e/ou pelas instituições escolares como relevantes e necessários à formação dos alunos em um dado nível de ensino. Os saberes da experiência ou saberes da prática, que se referem aos saberes especificamente desenvolvidos no exercício da docência e na prática profissional e fundamentados e validados pela experiência dos professores no seu meio e no dia a dia. (GRIGOLLI, 2003, p. 112-113).
\end{abstract}

Considerando as diferentes fontes de aquisição de conhecimentos e saberes por parte dos(as) discentes, bem como reconhecendo seu valor na formação docente em Educação Física, acreditamos que o acesso a esses saberes deva ser estimulado por ações pedagógicas que transformem a aprendizagem em uma experiência intelectualmente instigante e socialmente relevante. Para isso, é indispensável que a prática pedagógica de professoras(es) universitárias(os) valorize a cultura geral, trazendo à tona conteúdos que se apresentem como socialmente distantes dos currículos, mas que, sobretudo, estejam capacitadas(os) didática e pedagogicamente para fazê-lo. Corroborando tais assertivas, a partir de outras experiências pedagógicas com temática similar, Araújo, Pádua e Dias (2013, p. 118) nos trazem que:

Incentivar espaços de aprendizagem que recuperem experiências do cotidiano e/ou representações da produção cultural para pensar sua área de formação é uma ação que visa contribuir para a formação pessoal do professorado em formação além de promover uma reflexão coletiva de como os saberes pessoais e da for- 
mação escolar ecoam em nossa forma de pensar a prática docente em Educação Física.

A partir desse contexto, acreditamos que assistir a filmes constitui prática social e pedagógica tão relevante quanto as outras formas de apreensão de conhecimentos, mostrando-se, portanto, como um importante recurso didático na aprendizagem e nas reflexões durante o processo de formação. A intencionalidade pedagógica na escolha das narrativas, a clareza no objetivo da utilização desse recurso didático, o debate a partir das problematizações dos temas apresentados, o estudo crítico do enredo do filme, assim como a articulação com a realidade dos(as) discentes, no tempo histórico e no espaço, são possibilidades potentes de ressignificação do processo ensino-aprendizagem na formação superior.

Em estudos recentes, Maldonado et al. (2018) buscaram identificar de que formas a utilização do cinema como recurso pedagógico inovador estava sendo relatado nos artigos científicos no campo da educação física. Percebe-se o aumento nesse processo de utilização das produções fílmicas no processo de ensino e aprendizagem, bem como a diversificação das experiências pedagógicas.

Paralelamente, Tinôco e Araújo (2017) mapearam a produção acadêmica nacional sobre a temática "cinema e educação física" e identificaram, além de um número reduzido de produções, limitações acerca da utilização dos artefatos fílmicos nas experiências pedagógicas, que figuraram em boa parte dos processos como auxiliares ou meros coadjuvantes.

A partir dessas ideias e considerações, e tendo em vista que tais experiências pedagógicas são provisórias e estão em constante redimensionamento e aprofundamento e são merecedoras de registro e divulgação, apresentaremos neste ensaio um conjunto de processos pedagógicos com o uso de filmes realizados entre os anos de 2014 e 2017, em algumas disciplinas do curso de graduação em Educação Física da Faculdade de Educação Física e Desportos (FAEFID) da Universidade Federal de Juiz de Fora (UFJF), intitulado "Cinema e Educação Física em Debate". Essa experiência, que entende o cinema como um instrumento de formação, foi elaborada pelo Programa de Educação Tutorial (PET $\left.{ }^{6}\right)$ da FAEFID.

"Cinema e Educação Física em Debate" trouxe como proposta a articulação entre o recurso audiovisual e os saberes e práticas da Educação Física, ampliando as discussões e interpretações de temas sobre gênero e práticas corporais e esportivas, os quais nem sempre são privilegiados pelos saberes curriculares e disciplinares na formação docente em Educação Física na FAEFID.

O processo de exposição do projeto seguirá o seguinte norteamento: i) a estratégia construída para a intervenção pedagógica com o uso do cinema na discussão do tema de gênero e práticas corporais e esportivas na graduação em Educação Física; ii) os filmes que privilegiamos e que estão ligados a temas como gênero, masculinidades, feminilidades, sexualidades, educação, esporte, dança, corpo, política e história; e iii) os saberes que produzimos com

6 Nomeado inicialmente "Programa Especial de Treinamento" pela Coordenadoria de Aperfeiçoamento de Pessoal de Nível Superior (CAPES), foi criado em 1979 e regulamentado pela Lei N ${ }^{\circ} 11.180$, de setembro de 2005. O Programa é destinado a apoiar grupos de discentes que demonstrem potencial, interesse e habilidades destacadas em cursos de graduação das Instituições de Ensino Superior e compõe-se de grupos tutoriais de aprendizagem, buscando propiciar aos alunos, sob a orientação de um professor-tutor, condições para a realização de atividades extracurriculares que complementem a sua formação acadêmica. Assim, constitui-se uma modalidade de investimento acadêmico em cursos de graduação que tem compromissos epistemológicos, pedagógicos, éticos e sociais. Busca-se, dessa forma, a produção de práticas sociais emancipatórias nos eixos de ensino, pesquisa e extensão. Especificamente sobre o PET/FAEFID, cabe apontar que a FAEFID/UFJF iniciou as suas atividades em 2009. O programa de Educação Tutorial tem como um dos seus princípios mediar o currículo e a formação nos cursos de graduação, em estreita relação com os discentes e com a comunidade acadêmica, favorecendo uma formação tanto para integração no mercado profissional quanto para o desenvolvimento da pesquisa. Além disso, garante aos graduandos a oportunidade de vivenciar experiências não presentes nas estruturas curriculares convencionais, visando a sua formação global e cultural. 
os alunos de graduação e pós-graduação como desdobramentos a partir das intervenções realizadas.

Além disso, destacaremos algumas percepções provisórias sobre tais processos pedagógicos nesse contexto educacional à luz de alguns referenciais teóricos sobre a análise fílmica e suas apropriações no campo educacional.

\section{Experiências pedagógicas diversas: aspectos de um processo em construção}

O grupo tutorial PET-FAEFID planejou o projeto "Cinema e Educação Física em Debate" com a finalidade de propor uma experiência diferenciada da perspectiva convencional de educação superior baseada em um conjunto qualitativamente limitado de conteúdos curriculares, e teve como missão estimular a aprendizagem ativa ${ }^{7}$ dos seus membros por meio de vivências, reflexões e discussões, em clima de "informalidade" e cooperação.

Nesse sentido, formulou-se o referido projeto e iniciou-se discussões sobre as estratégias de desenvolvimento da experiência. Optou-se pela metodologia baseada na pesquisaação, definida como tentativa continuada, sistemática e empiricamente fundamentada de aprimorar a prática docente. Algumas questões comuns relativas ao método são: a participação, o papel da reflexão, a necessidade de administração do conhecimento e a ética do processo (TRIPP, 2005).

A seleção dos filmes que apresentaremos teve como referência a temática de gênero e práticas corporais e esportivas. E o conjunto de disciplinas do curso de graduação em Educação Física que acolheram esta experiência do PET-FAEFID foram: Ensino de Lutas; Educação Física, Escola e Juventude; Educação Física, Escola e Infância; Educação Física Inclusiva. Para o desenvolvimento da intervenção pedagógica, os seguintes procedimentos foram adotados:

a) Seleção de filmes em que o tema gênero, práticas corporais e esportivas fosse transversal aos conhecimentos das disciplinas do curso de Educação Física em que foram realizadas as intervenções;

b) Agendamento de uma aula da disciplina com o professor responsável para a projeção do filme, com a participação do professor da disciplina e do professor colaborador do PET e debatedor do filme;

c) O professor colaborador que tem a função de debatedor do filme, nesta experiência, é um docente da disciplina ou convidado pelo PET-FAEFID, normalmente um estudioso/pesquisador do tema central do filme, o qual se incumbia de selecionar as leituras anteriores à exibição do filme para serem enviadas ao grupo/turma e de organizava sua fala após a projeção, com duração de quarenta minutos entre o debate, as provocações e as perguntas. Divulgação da sessão no site do PET-FAEFID e da FAEFID nas redes sociais, o que possibilitou a ampliação da presença de alunos de outros cursos e períodos, além daqueles matriculados na disciplina;

d) Indicação de textos e artigos sobre o filme para leitura, a fim de subsidiar o debate após a sessão;

e) Projeção e debate do filme conduzido pelo professor colaborador do PET junto aos participantes da sessão;

f) Participação dos integrantes do PET-FAEFID no registro da experiência.

7 O método tutorial permite o desenvolvimento de habilidades de resolução de problemas e pensamento crítico entre os bolsistas, e oportuniza aos estudantes se tornarem cada vez mais independentes em relação à administração de suas necessidades de aprendizagem. 
Para apresentação neste ensaio, elegemos as experiências com os filmes "Menina de Ouro", "OffSide", "Driblando o Destino" e "Billy Eliot".

Em Menina de Ouro (2004), de Clint Eastwood, refletimos sobre as representações de feminilidade no boxe para mulheres. A personagem principal da trama, Maggie, incorpora uma "lutadora" dentro e fora dos ringues. É uma mulher determinada, que assume seus objetivos enfrentando preconceitos e pressões sociais e, assim, afirma feminilidades caracterizadas pela força e virilidade, o que contribui para o processo de desconstrução do mito da fragilidade, historicamente imputado às mulheres, especialmente na prática de esportes. Esse filme possibilitou discussões acerca dos processos de transformações na configuração das representações de gênero, de sexualidades, étnicas, políticas, econômicas e de classe em uma sociedade. Na condição de uma categoria de análise, entendemos o gênero como:

A condição social por meio da qual nos identificamos como masculinos e femininos. É diferente de sexo, termo usado para identificar as características anatômicas que diferenciam os homens das mulheres e vice-versa. O gênero, portanto, não é algo que está dado, mas é construído social e culturalmente e envolve um conjunto de processos que vão marcando os corpos, a partir daquilo que se identifica ser masculino e/ou feminino. (GOELLNER, 2010, p. 75, grifo da autora).

O gênero abrange melhor o que as diversas sociedades e culturas humanas representam sobre feminino e/ou masculino. Nesse sentido, observa-se que a base identitária do gênero é dada pela repetição estilizada dos atos através do tempo, e que as possibilidades de transformação se encontram nas relações arbitrárias entre esses atos, na possibilidade de outras formas de repetição ou ainda na quebra da repetição subversiva desse estilo (BUTLER, 2010).

No âmbito das práticas esportivas, que se apresentam como espaço social na contemporaneidade de experiências corporais e relações de poder intensas (DANTAS JÚNIOR, 2013), o boxe está historicamente associado ao desenvolvimento e à demonstração de significados ligados à virilidade, força física, agilidade, assim como do controle da dor e do corpo: características que representam o ideal de masculinidade (WACQUANT, 2002). Esse debate faz-se necessário para esclarecer os modos como tal prática corporal vem sendo historicamente construída, de modo a "interditar" as experiências de mulheres na modalidade, o que, em última instância, problematiza as posições e ocupações sociais de mulheres e homens numa dada sociedade, a partir de normas que se edificam sobre discursos biológicos das "diferenças sexuais".

Como fruto dos debates suscitados junto à graduação no projeto "Cinema e Educação Física em Debate", em outubro de 2014, foi publicado na revista científica "Movimento" o artigo intitulado "Menina de Ouro e a representação de feminilidades plurais" (FERNANDES; MOURÃO, 2014) ${ }^{8}$, que objetivou apreender o discurso social vigente sobre a temática do envolvimento feminino em práticas esportivas de combate, como o boxe. Por meio da análise do filme, foi possível perceber a participação do boxe na construção de formas plurais de feminilidades marcadas por força, determinação, ousadia, virilidade, garra e coragem, evidenciando-se que a escolha pelo boxe é feita por mulheres audaciosas que querem experimentar outras formas de se construírem femininas.

Dando prosseguimento ao projeto, o filme iraniano "OffSide" (2006), de Jafar Panahi, vencedor do prêmio "Urso de Prata", no festival de Berlim (2006), discorre sobre um grupo

\footnotetext{
8 Esse artigo também foi utilizado como fonte para a construção de uma questão do ENEM (Exame Nacional do Ensino Médio), no ano de 2016. É importante destacar o interesse da temática pelos professores que formularam a questão, levando milhões de alunas(os) a refletirem sobre as questões de gênero e práticas corporais e esportivas.
} 
de mulheres que desafia a lei no Irã ao tentar assistir a uma partida de futebol. No Irã, as mulheres gostam de futebol, mas são proibidas de irem ao estádio. $\mathrm{O}$ desejo de assistir ao jogo decisivo para a classificação da seleção iraniana para a Copa do Mundo de 2006 leva as fãs a se disfarçam de homens, tentando enganar a polícia de costumes do estádio. O filme problematiza as questões de gênero a partir da ousadia de algumas meninas que vivem de forma protagonista a sua condição de mulher nessa sociedade.

Desde a Revolução Islâmica de 1979, as mulheres foram proibidas de irem ao estádio para assistir aos jogos de futebol masculino, sob a justificativa de protegê-las das injúrias e do comportamento vulgar dos torcedores. Aquelas que porventura se disfarçam e entram nos estádios são consideradas como prostitutas pelos vigilantes, ou seja, sofrem discriminações e preconceitos, sobretudo, dos líderes religiosos.

Outro filme selecionado foi "Driblando o Destino" (2002), de Gurinder Chadha, que traz uma narrativa sobre o sonho de Jesminder Bhamra: seguir o caminho de seu ídolo David Beckham e tornar-se uma jogadora profissional de futebol. Entretanto, ela enfrenta problemas em sua família, a qual deseja que ela siga os costumes indianos tradicionais, assim como sua irmã mais velha, Pinky. Seu pai sempre a incentivou a jogar bola, mas a mãe acha que isso não é "coisa para menina". O confronto entre as partes chega ao ápice quando Jesminder é obrigada a escolher entre a tradição de seu povo e seu grande sonho.

Por último, "Billy Elliot" (2000), produção de Stephen Dalry, que narra a história de um garoto de 11 anos, órfão de mãe, que pratica boxe (uma tradição entre os homens da família) na academia de um bairro proletário de uma pequena cidade da Inglaterra, no século XX. Billy, entretanto, não apresentava habilidade para boxe; seus golpes não eram desferidos com destreza e vigor, tampouco apreciados pela maioria. Certo dia, o jovem se encanta pelas aulas de ballet que passam a acontecer na academia onde pratica boxe. Os passos de dança, combinados com a música clássica, tornam-se cada vez mais atrativos para o menino. Esse interesse, contudo, transformou-se em um problema para sua família, principalmente para seu pai, que não aceitava a ideia de Billy se tornar um bailarino, pois tinha a convicção de que era uma prática corporal para mulheres. Para eles, Billy deveria continuar lutando boxe, por acreditarem que um homem é identificado a partir de sua força e sua virilidade praticadas na luta. A possibilidade de se tornar um bailarino representava, para o seu pai, a suspeição de sua sexualidade. $\mathrm{O}$ talento reconhecido pela professora e a mentalidade intolerante e opressora reinantes na região onde Billy vive se chocam em uma história emocionante, que parece se repetir em muitos lugares do mundo.

Acerca do ocorrido frente à intervenção realizada com o filme "Menina de Ouro", Lovisi e Mourão (2012) escreveram um capítulo intitulado "Corpo e gênero: na tela com Billy Elliot", publicado no livro "Políticas e poéticas das imagens como processos educativos", organizado por Ferrari e Castro (2012). Nesse texto, são apresentadas as dificuldades enfrentadas pelo menino, que vive em uma família tradicional e machista, por escolher praticar ballet em vez de boxe. A partir das situações apresentadas no filme, foi possível realizar discussões sobre: corpo, gênero, identidade, diferença, práticas esportivas aceitas e adequadas a cada gênero, sexualidade, tolerância - temas relevantes para a educação dos valores humanos das crianças e jovens na contemporaneidade.

Os filmes, portanto, foram dispositivos de análise para problematizar situações vividas em nosso cotidiano relativas à cultura corporal, em que meninas e meninos são motivados (ou interditados) a praticar determinados esportes, de acordo com o gênero. Tomamos como referência, para as discussões, cenas que nos levaram a questionar as relações entre cultura corporal, masculinidades e feminilidades relacionadas às normas e convenções do futebol, do boxe e da dança, nas relações de gênero e sexualidade. 


\section{Outras construções inspiradas no projeto}

A experiência do PET-FAEFID com a utilização de filmes na formação inicial apresentou vários desdobramentos a partir das experiências vividas por alunos da graduação, que os subjetivaram de diferentes formas, possibilitando a produção de diversos saberes a partir das sínteses que realizaram. A formação cultural e curricular, por exemplo, estendeu-se em elaboração de TCCs, produção de artigos científicos, capítulos de livro e apresentações de trabalhos em congressos.

Com a intenção de inter-relacionar os temas transversais propostos pelos Parâmetros Curriculares Nacionais (BRASIL, 1997), como identidade e diferença, discriminação, tolerância, homofobia e gênero com alunos do Ensino Fundamental nas aulas de Educação Física, Valle e Vilaça (2013) construíram um estudo monográfico com o objetivo de abordar esses temas por intermédio do cinema, com o filme "Minha Vida em Cor de Rosa",

Por meio de questões problematizadoras e provocativas, as autoras analisaram as narrativas produzidas pelos alunos sobre algumas cenas do filme. A pesquisa realizada levou os alunos a concluírem que o cinema é um importante artefato pedagógico, capaz de desencadear, através das imagens, diferentes sentimentos, levando-os a refletir sobre suas atitudes, relações e interações. Os filmes, embora não reflitam a realidade de forma linear, de acordo com Melo (2006), trazem consigo olhares de uma sociedade e, ao mesmo tempo, intencionalidades sobre ela, sendo capaz de exercer influência na formação dos indivíduos.

Motivada em analisar o esporte como possibilidade e ferramenta de luta social, por meio de construções fílmicas, a graduanda Martins (2014) construiu um TCC com o objetivo de analisar o rugby na luta de Nelson Mandela contra a desigualdade racial e social na África do Sul, a partir do filme "Invictus" . As discussões versaram sobre a análise de três cenas do filme, que possibilitavam a compreensão sobre o surgimento de uma nova África do Sul, considerando o esporte como um importante meio utilizado por Nelson Mandela para diminuir o preconceito racial estabelecido na sociedade. O estudo mostra que debater esporte e gênero como um meio educativo, de formação de identidades, pode ser de grande valia para a Educação Física, não só em relação às questões étnicas e de classes, mas também em outros aspectos que constituem a formação política de cidadãos críticos.

\footnotetext{
9 Dirigido por Alain Berliner, de origem francesa, foi lançado em 1997. A trama conta as desventuras do garoto Ludovic, que cresceu imaginando ter nascido no corpo errado: ele acredita ser uma menina. Logo na primeira sequência, em uma festinha promovida pelos pais para atrair a nova vizinhança, ele aparece em um lindo vestidinho. Essa aparição causou certo mal-estar na maioria dos presentes, que começaram a pressionar e ridicularizar o garoto. A rejeição se estende aos pais, aos colegas e a qualquer um que se aproximasse de um sintoma de homossexualidade tão latente. Ludovic refugia-se do tormento em um mundo róseo, onde só cabem a boneca Pam, uma Barbie espevitada, e o apoio afetivo da avó (Helene Vincent). Com um enfoque engraçado, o filme passa uma mensagem edificante de convivência com as diferenças.

10 Baseado na história real da disputa da Copa do Mundo de Rugby, em 1995, "Invictus" foi dirigido pelo premiado cineasta Clint Eastwood. O filme foi produzido nos Estados Unidos e lançado no ano de 2009. A história se passa em 1994, quando Nelson Mandela se torna presidente da África do Sul, recebendo um país dividido pela disputa racial. Enquanto os negros comemoram sua vitória e sonham com uma nação mais justa, os brancos vivem outra realidade e têm como símbolo maior de seu patriotismo o desacreditado time de rugby. A proximidade da Copa do Mundo de Rugby, em 1995, faz com que a disputa racial invada os estádios, com os negros torcendo pela seleção da Inglaterra. Disposto a usar a linguagem universal do esporte para unir seu povo, Mandela pede ajuda ao capitão da seleção africana. O presidente, então, convoca o jovem, para juntos transformarem o time de rugby em uma seleção competitiva capaz de disputar o título. A união do poderoso líder negro com o jovem esportista branco possibilita à África do Sul conseguir uma campanha inacreditável no campeonato, ajudando a alavancar uma paixão comum para toda a população do país.
} 


\section{Considerações Finais}

A partir das experiências pedagógicas relatadas neste ensaio, percebemos como o cinema torna-se um importante recurso audiovisual na mediação do processo de formação docente, possibilitando uma inter-relação entre a formação acadêmica, cultural e social. Isso ocorre em consequência da sua linguagem, capaz de articular imagem e som, com o objetivo de abordar conceitos, ideias, informações e significados diversos, além de ser um potencializador de reflexões e debates.

Essa elocução proporciona aos discentes uma linguagem estética singular em sua formação, pois desenvolve de forma crítica a leitura da realidade social através das experiências culturais formativas.

Acreditamos que as experiências realizadas pelo projeto "Cinema e Educação Física em Debate" constituíram-se em uma forma de abordar o tema do gênero e práticas corporais, dialogando com diferentes disciplinas e subjetivando as(os) docentes e discentes de diferentes formas, o que nos motiva a partilhar e ampliar tais possibilidades pedagógicas.

Assim, o êxito do projeto não se baseia somente nos desdobramentos de sua realização, mas também na relevância de sua vivência. Tais experiências demonstram ser possível trabalhar a instrumentalização dos filmes no ensino superior de forma transversal e interdisciplinar aos conhecimentos das disciplinas do currículo. Dessa feita, partilhar tal experiência é uma forma de ampliar as alternativas dos docentes ao abordarem temáticas ainda não incluídas nos currículos da formação de professores de Educação Física, assim como aquelas já incluídas, abordadas a partir de outros artefatos culturais, como o cinema.

\section{Referências}

ARAÚJO, Allyson Carvalho; SANTOS, Antônio de Pádua; DIAS, Maria Aparecida. O que se pode aprender em uma sala escura? Relatos e notas sobre educação e cinema. Atos de pesquisa em educação, Blumenau-SC, v. 8, n.1, p.111-128, jan./abr., 2013.

BITTENCOURT, Circe Maria Fernandes. Ensino de história: fundamentos e métodos. São Paulo: Cortez Editora, 2004.

BRASIL. Parâmetros curriculares nacionais: introdução aos parâmetros curriculares nacionais / Secretaria de Educação Fundamental. Brasília: MEC/SEF, 1997.

BUTLER, Judith. Problemas de gênero: feminismo e subversão da identidade. Tradução de Renato Aguiar. Rio de Janeiro: Civilização Brasileira, 2010.

DANTAS JUNIOR, Hamilcar Silveira. Esporte e cinema na escola: usos pedagógicos para uma educação esportiva. Atos de pesquisa em educação, Blumenau-SC, v. 8, n. 1, p. 361385, jan./abr., 2013.

DUARTE, Rosália. Cinema \& educação. 3. ed. Belo Horizonte: Autêntica, 2009.

FABRIS, Ellí Terezinha Henn. Em cartaz: o cinema brasileiro produzindo sentidos sobre a escola e o trabalho docente. Dissertação (Mestrado em Educação) - Universidade Federal do Rio Grande do Sul: Porto alegre, 2005. 
FERNANDES, Vera; MOURÃO, Ludmila Nunes. "Menina de Ouro" e a representação das feminilidades plurais. Porto Alegre: Revista Movimento, Porto Alegre, RS, v. 20, n. 4, p. 1611-1629, out./dez. 2014.

FERRARI, A. (org.). A potencialidade do conceito de experiência para a educação. Juiz de Fora: Editora UFJF, 2012.

FOUCAULT, Michel. Sobre a história da sexualidade. In: FOUCAULT, Michel. Microfísica do poder. 25. ed. Rio de Janeiro: Graal, 2012. p. 364.

FOUCAULT, Michel. A ordem do discurso: aula inaugural no Collège de France pronunciada em 2 de dezembro de 1970. 21. ed. São Paulo: Loyola, 2011.

GOELLNER, Silvana Vilodre. A educação dos corpos, dos gêneros e das sexualidades e o reconhecimento da diversidade. Cadernos de Formação RBCE, Florianópolis, v. 1, n. 2, p. 71-83, 2010.

GRIGOLLI, Josefa Aparecida Gonçalves et al. Saberes dos professores e ambiguidades da prática docente na rede pública de Campo Grande, MS. In: OSÓRIO, Alda Maria do Nascimento. (org.). Trabalho docente: os professores e sua formação. Campo Grande, MS: Ed. UFMS, 2003.

LOVISI, Ayra; MOURÃO, Ludmila Nunes. Corpo e gênero: na tela com Billy Elliot. In FERRARI, Anderson; CASTRO, Roney Polato (org.). Política e poética das imagens como processos educativos. Juiz de Fora: Ed. UFJF, 2012.

MALDONADO, Daniel Teixeira et al. Inovação na educação física escolar: desafiando a previsível imutabilidade didático-pedagógica. Pensar a prática, Goiânia-GO, v. 21, n.2, abr./jun. 2018.

MARTIN, Marcel. A linguagem cinematográfica. 1. ed. São Paulo: Brasiliense, 2009.

MARTINS, Raquel Oliveira Mendonça. Invictus: o rugby como agente transformador social no contexto histórico e político da África do Sul. 2014. Trabalho de Conclusão de Curso. (Graduação Educação Física) - Universidade Federal de Juiz de Fora, Juiz de Fora, 2014.

MELO, Victor Andrade de. Animação cultural: conceitos e propostas. Campinas: Papirus, 2006.

OLIVEIRA-SILVA. Geraldo Magela. Cinema e formação de professores em cursos de licenciatura. Dissertação (Mestrado em Educação) - Universidade Estadual do Ceará, Fortaleza, 2013.

TARDIF, Maurice. Saberes docentes e formação profissional. 7. ed. Petrópolis, RJ: Vozes, 2002.

TINÔCO, Rafal de Góis; ARAÚJO, Allyson Carvalho. Cinema e educação física escolar: estado da $7^{\mathrm{a}}$ arte. Pensar a prática. Goiânia-GO, v.20, n.4, out./dez. 2017.

TRIPP, David. Pesquisa-ação: uma introdução metodológica. Educação e Pesquisa, São Paulo, v. 31, n. 3, São Paulo, set./dez. 2005. 
WACQUANT, Loïc. Corpo e alma: notas etnográficas de um aprendiz de boxe. Rio de Janeiro: Relume Dumará, 2002.

VALLE, Mara; VILAÇA, Tábata. Sexualidade, cinema e educação física: nas telas com minha vida em cor de rosa. 2013. Trabalho de Conclusão de Curso (Graduação em Educação Física) - Universidade Federal de Juiz de Fora, Juiz de Fora, 2013.

Recebido em: 10/07/2018

Revisado em: 08/09/2018

Aprovado em: 08/12/2018

Endereço para correspondência:

joaopaulosoaresufjf@gmail.com

João Paulo Fernandes Soares

Universidade Federal de Juiz de Fora

Departamento de Educação Física e Desportos

Rua Israel Pinheiro - até 2625/2626

São Pedro

35020220 - Governador Valadares, MG - Brasil 